\title{
REPOSITORY ENGINEERED BARRIER SYSTEM DESIGN
}

\author{
Daniel G. McKenzie, III PE, Morrison Knudsen Corporation \\ 1180 Town Center Drive, Las Vegas, Nevada 89134
Dr. Kalyan K. Bhattacharyya, Morrison Knudsen Corporation 1180 Town Center Drive, Las Vegas, Nevada 89134

Paul G. Harrington, U.S. Department of Energy

1551 Hillshire Drive, Las Vegas, Nevada 89134

\begin{abstract}
A Viability Assessment (VA) for the Yucca Mountain Project is being completed for delivery in September of 1998. A major element of the VA is the design of a high level waste repository on the Nevada Test Site. The repository is made up of surface and subsurface facilities. The engineered barrier includes the manmade elements of the system that act to retard the migration of radionuclides from a geologic repository. They act in conjunction with the geologic barriers present at Yucca Mountain. The engineered barrier system (EBS) consists of the Waste Package and the underground facility. The focus of this paper is the status of the design of the underground facility portion of the EBS.
\end{abstract}

In addition to a robust waste package, the EBS components in the reference design include a number of features that impede naturally occurring infiltration from reaching and corroding the waste packages. In addition, and as a defense-in-depth strategy, a number of other optional features are being considered. They include drip shields above the waste packages to intercept dripping water and granular backfill around the waste packages to form a diffusion barrier. Plans are being made to test a number of the EBS materials and structures.

The Viability Assessment document will discuss the various EBS options and alternative designs and lay out a plan for determining those to be included in the License Application to the Nuclear Regulatory Commission (NRC) scheduled for completion in 2002.

\section{Introduction}

Yucca Mountain, located approximately 160 kilometers northwest of Las Vegas, Nevada, is currently being characterized to ascertain its suitability to house a geologic repository. This repository, if constructed, will provide for disposal of 70,000 Metric Tons Uranium (MTU) of commercial spent nuclear fuel, vitrified defense high level waste, and DOE spent nuclear fuel (SNF). The U.S. Congress, in its 1997 appropriations bill for Yucca Mountain, directed that the DOE conduct a "Viability Assessment" of the program. This VA is to consist of four primary components: (1) a description of the repository and waste package designs, focusing on the critical elements; (2) a total system performance assessment of that design to provide an indication of its long-term waste isolation capabilities; (3) a cost estimate for the design, construction, operation, and closure of the facility; and (4) a detailed plan and cost estimate to proceed to submittal of a license application.

A repository at Yucca Mountain will consist of surface facilities to receive, handle, and package the arriving wastes, and a subsurface facility where the waste packages will be placed for monitoring and, ultimately, disposal. The system of "Engineered Barriers" is made up of those man-made attributes of the facility that contribute to the long-term isolation of the wastes. The primary components of the EBS are the waste package and the underground facility. The latter component forms the subject of this paper.

\section{The Repository Layout}

The repository layout, which is the framework of the underground facility, is shown in Figure 1. The layout involves a total of approximately 157,000 meters of tunneling, and makes use of the 7,800 meters of 
large-diameter tunneling already developed as part of the exploratory program (REF. 1). Approximately 300 hectares of emplacement area is needed for the planned waste inventory. The subsurface will be developed over the course of approximately 25 years. About $20 \%$ of the tunneling must be completed prior to the start of waste emplacement operations in 2010. The balance will be completed in parallel with ongoing waste emplacement operations. The main drifts, labeled on Figure 1, are planned to be excavated 7.62 meters in diameter with a $300 \mathrm{~mm}$-thick cast-in-place permanent concrete liner. The emplacement drifts will be excavated 5.5 meters in diameter, and will be equipped with a $200-\mathrm{mm}$ thick pre-cast concrete liner. Approximately $10 \%$ of the emplacement drifts will be supported by steel sets so that geologic mapping may be conducted. (REF. 2)

The arrangement of the repository drifting is a part of the EBS to the extent that it can minimize the ability of water to contact the waste packages. The waste emplacement strategy, the shape of the emplacement drifts, and the overall subsurface configuration all play a part in achieving this objective.

Emplacement Strategy - The emplacement strategy calls for the waste packages to be placed in a "high thermal loading" configuration. The commercial spent fuel and, to a significantly lesser extent, the defense wastes and DOE SNF, produce heat as a by-product of the decay process. When the waste packages are placed in an underground opening, their heat output raises the temperature of the surrounding rock. The arrangement and density at which the packages are emplaced determines the peak temperature experienced by the rock around the opening. If the emplacement density (the "thermal load") is high enough, most, or all, of the nearby rock will be heated above the boiling point of water. During the time that the emplacement drift environment is above boiling, it is expected that there will be very little chance of liquid water contacting the waste packages. The liquid water naturally contained in the rock pores and fractures will boil to steam, expand in volume, and be driven, via the fracture networks, away from the emplacement areas. Some water vapor may also enter the emplacement drift via the fracture network. During the preclosure period, a low continuous ventilation flow will be passed through the drifts. This flow will remove water vapor that enters the drift during the initial heat-up and throughout pre-closure. During the period when liquid water is absent, the corrosion rate of the waste packages should be very low. In this way, the arrangement of the subsurface drifts, in conjunction with the waste package emplacement arrangement, acts as an engineered barrier to inhibit waste package corrosion and delay the time when radionuclides can escape from degraded waste packages. The time period during which the drift temperatures will remain above boiling is strongly dependent on the waste characteristics and on the amount of water moving down through the host rock (termed "groundwater flux"). The above-boiling period is estimated to last from 1,000 to 3,000 years. (REF. 3)

Opening shape - The emplacement drifts, as well as the main drifts, are to be excavated using tunnel boring machines. These machines produce a round opening cross-section. During the time that the tunnel openings remain intact, water entering the upper half of a round drift will tend to run around the perimeter of the drift rather than to drip off the liner onto the waste package. While the bulk of the emplacement area should remain above boiling longer than the projected life of the tunnels, areas along the edges of the emplacement area, and areas subject to higher than normal fracture-flow rates of water, may tend to re-wet sooner. In areas where the temperature either does not reach boiling or drops relatively quickly below boiling, the tunnel shape should act as a deterrent to water dripping on the packages. Even in non-edge areas this deterrent will be present as long as the drift retains its original round configuration.

\section{The Drift-Scale Arrangement}

The previous segment has described how the features of the repository layout act as engineered barriers. This section will examine the repository on the scale of a single drift to discuss the individual components in the emplacement drift and their potential to act as engineered barriers. Figure 2 is a cross-section of an emplacement drift showing the pre-cast concrete liner, the waste package support system, and the waste package.

Drift Liner - The primary function of the drift liner is to provide a stable opening during the pre-closure period of the repository. However, because the liner is a permanent installation, it will remain a part of the drift environment in perpetuity. The liner is not a primary EBS component, but it does provide a defense- 
in-depth function by helping to maintain the round configuration of the drift, at least during the early postclosure period. In addition, it can be installed such that it has no joints directly above the waste package. This would be accomplished by installing the tightening wedge off-center instead of in the top center of the drift. The absence of joints directly above the package should further discourage drips directly onto the package during the early post-closure period, as long as the liner remains intact.

Waste package support system - The support system consists of the drift invert segment (also an integral part of the drift liner system), the pier, and the waste package support. These items combine to keep the package elevated above the floor of the drift. During the pre-closure period, this elevation is important because it allows the package to more evenly radiate its heat to the surrounding drift walls and floor. If it were laid directly on the floor, it would not be able to radiate heat effectively to the floor, causing hot spots that could result in the package internal temperature goal being exceeded. In the post-closure, the support will corrode and eventually fail, as will the underlying pier. However, even in the degraded state, the remnants of the support and pier may help to keep the much longer-lived waste package off the floor of the drift and out of any small amount of water which could enter the drift.

\section{Optional EBS Features}

The VA design as shown in Figure 2 and previously discussed, will provide adequate performance, based on current Total System Performance Assessment predictions. However, the final standard of performance is not yet available, and the current predictions of adequacy are based on an assumed standard. If the final standard is set at a lower value, or conditions as they are currently perceived change, or if it is desired to increase the margin for long-term repository performance, it may be possible to improve the performance by the addition of optional features. These features could include the placement of backfill in the emplacement drifts, the use of "dripshields" over the waste package to retard water contact, or the application of a ceramic coating to the outside surface of the waste package to further prolong its life. The use of either dripshields or ceramic coatings also involves the use of backfill. The backfill is needed to protect the dripshield and/or ceramic coating from the eventual degradation of the emplacement drift. Backfill can also reduce the extent of drift collapse by limiting the void space available. Figure 3 shows an emplacement drift view with backfill, a ceramic-coated waste package, and a dripshield. The dripshield and ceramic coating are independent; either could be used without the other.

Backfill - The current backfill option consists of a granular, free-flowing material. Both crushed, screened mined rock from the excavation of the repository, and quartz sand are being considered as the fill material. Other materials, such as those having sorptive properties, may be considered as additives. Due to the high radiation dose rate of the waste packages, backfill would be emplaced remotely. The backfill would be placed in a single pass, starting at the point farthest from the drift entrance and retreating out to the entrance. Once backfill is placed in the drift, it would no longer be accessible to rail equipment. For this reason, backfill would only be emplaced after the decision is made to close the repository. (REF. 4)

Dripshields - A dripshield is any one of several concepts that place a long-lived barrier above the waste package to prevent liquid water from dripping on the package surface. Because the dripshield, to be useful, must have a lifetime that far exceeds the probable lifetime of the intact emplacement drift, backfill is required to provide protection for the dripshield from the eventual degradation of the drift. In order to provide longevity, the dripshield may need to be fabricated of the nickel-based alloy C-22 ${ }^{\mathrm{TM}}$ (similar to the waste package inner barrier) or a titanium alloy. The dripshield could be placed over the package at the time of package emplacement, or could be deferred until closure and placed just prior to the backfill. A traveling gantry, similar to that used to emplace the waste packages, could be used to set the dripshields in place. (REF. 5) 


\section{Summary}

The overall repository drift arrangement, as well as the drift-scale configuration, is intended to contribute to the function of long-term waste isolation. The employment of a high thermal loading strategy focuses heat and creates a dry zone around much of the repository emplacement area. In those areas which do not heat up, or which cool more rapidly, the shape of the drifts and the robust ground support contribute to the goal of keeping water away from the emplaced waste. The reference design includes a robust waste package and a system of support to place the package properly. If improved performance is desired or needed, there are a number of optional engineered barriers that can be employed to provide improved long-term performance.

\section{REFERENCES}

1. Civilian Radioactive Waste Management System - Management and Operating Contractor (CRWMS-M\&O), Repository Subsurface Layout Configuration Analysis, BCA000000-017170200-00008 Rev 00, July 1997.

2. CRWMS-M\&O, Controlled Design Assumptions Document, B00000000-01717-4600-00032 Rev 04/ICN04, March 1998.

3. CRWMS-M\&O, Thermal Loading Study for FY1996, B00000000-01717-5705-00044, Rev 01, November 1996.

4. CRWMS-M\&O, Engineered Barrier System Performance Requirements Study Report, BB0000000-01717-5705-00001 Rev 04/ICN04, March 1998.

5. CRWMS-M\&O, Constructibility Analysis of Backfill and Drip Shield Configurations, BCAH00000-01717-0200-00002 Rev 00B [Will be final prior to paper release] 


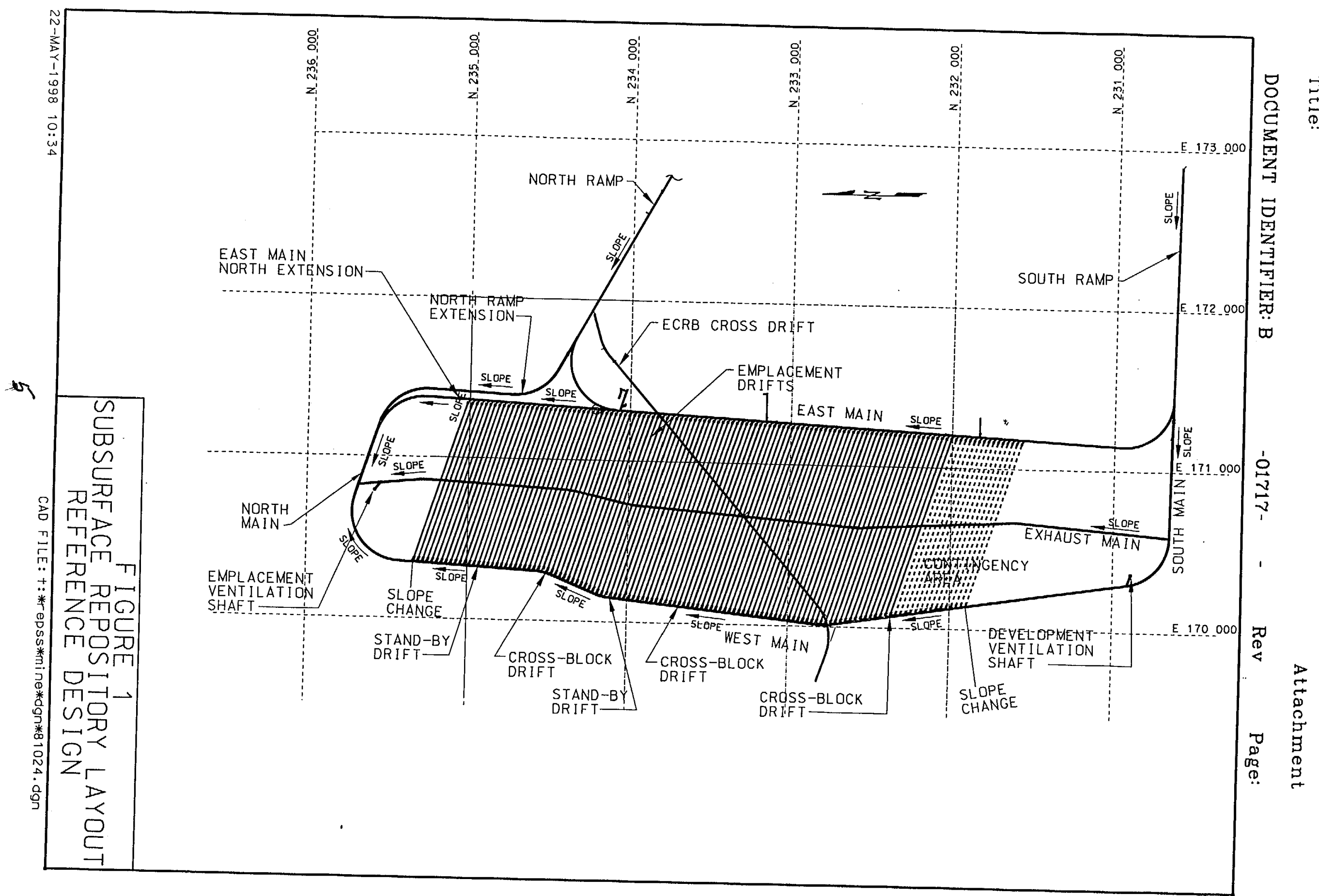




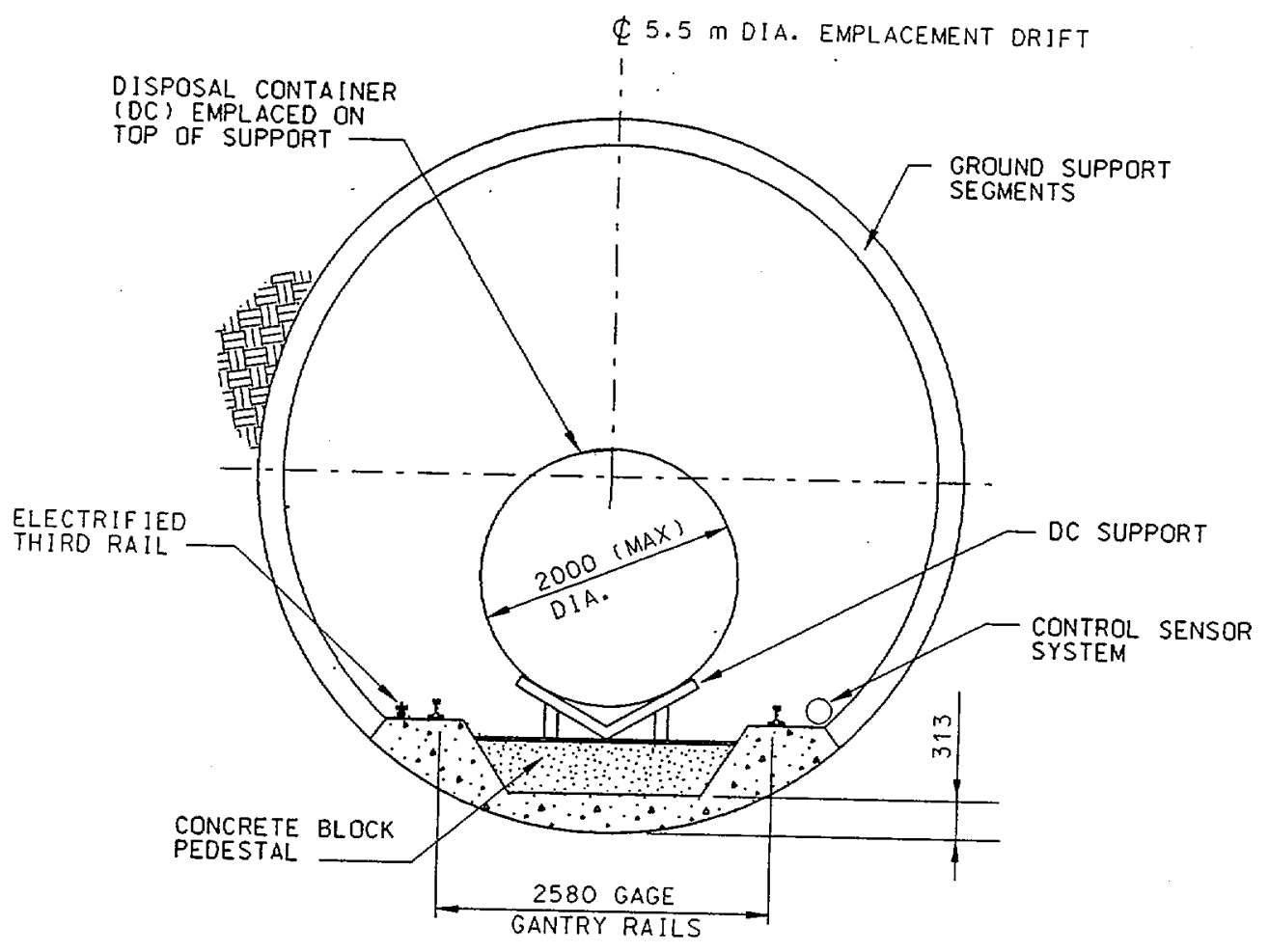

FIGURE 2
EMPLACEMENT DR IFT SECTION
AT DC SUPPORT LOCATION

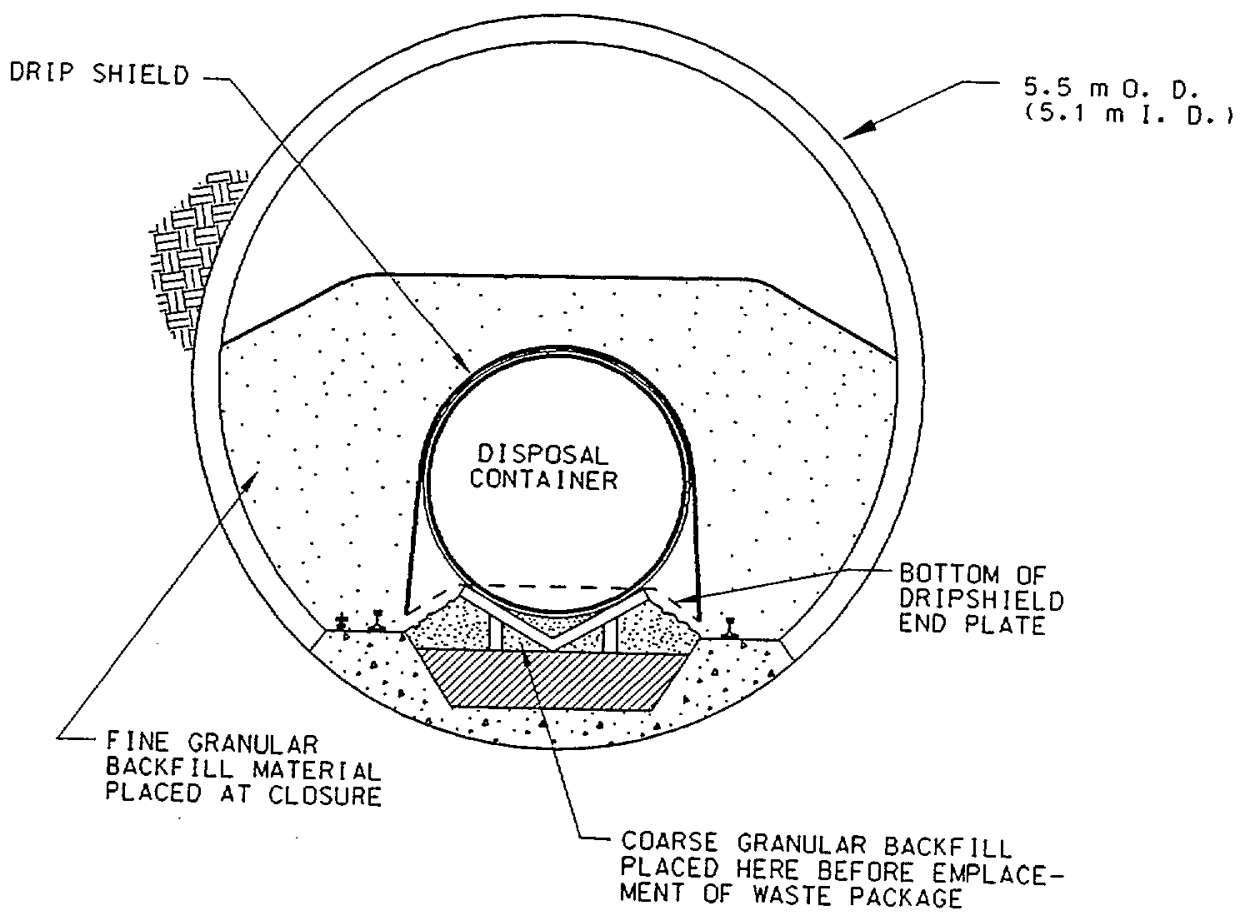

FI GURE 3

REFERENCE DESIGN WITH

DRIP SHIELD \& BACKF ILL 